\title{
Huntington's disease predictive testing: the case for an assessment approach to requests from adolescents
}

\author{
Julia Binedell, Jo R Soldan, Jane Scourfield, Peter S Harper
}

\begin{abstract}
Adolescents who are actively requesting Huntington's predictive testing of their own accord pose a dilemma to those providing testing. In the absence of empirical evidence as regards the impact of genetic testing on minors, current policy and guidelines, based on the ethical principles of non-maleficence and respect for individual autonomy and confidentiality, generally exclude the testing of minors. It is argued that adherence to an age based exclusion criterion in Huntington's disease predictive testing protocols is out of step with trends in UK case law concerning minors' consent to medical treatment. Furthermore, contributions from developmental psychology and research into adolescents' decision making competence suggest that adolescents can make informed choices about their health and personal lives. Criteria for developing an assessment approach to such requests are put forward and the implications of a case by case evaluation of competence to consent in terms of clinicians' tolerance for uncertainty are discussed.

( $f$ Med Genet 1996;33:912-918)
\end{abstract}

Key words: adolescence; Huntington's disease; predictive genetic testing.

Huntington's disease (HD), a currently incurable neuropsychiatric condition resulting in disturbances of movement, affect, and cognition with onset usually in adult life, is transmitted by an autosomal dominant gene which was identified in 1993 as an unstable CAG repeat sequence on the short arm of chromosome $4 .^{1}$ The discovery of the HD gene and the earlier existence of linked genetic markers ${ }^{2}$ has meant that people at risk of the disease have, for several years, been able to predict whether or not they will develop HD. Pretest counselling protocols have been carefully established to "set a standard of good practice for preparing and supporting persons who request predictive testing" ${ }^{3}$ and internationally agreed guidelines have been issued to "protect at risk persons" and "to assist clinicians, geneticists, and ethical committees as well as lay organisations to resolve difficulties arising from the application of the test". ${ }^{4}$ One of these guidelines precludes the testing of children under the age of 18 on the grounds that such profound decisions should not be made until the child concerned has reached legal majority and may consent for him/herself.

In response to recent requests for HD predictive testing, we have been prompted to reconsider our clinical practice in relation to testing of people under the age of 18. Most of the debate surrounding HD predictive testing of minors has focused on the predicament posed by third party/parental requests and the pros and cons of testing at such a young age. ${ }^{5-7}$ It is a different issue that we wish to address in this article, namely the dilemma posed by adolescents who are actively requesting HD predictive testing of their own accord. A survey of applications for linkage testing from four major European Community testing centres (in Belgium, Italy, The Netherlands, and UK) showed that five out of 39 referrals under 18 years of age were self-referrals, as opposed to requests made by parents or professionals. ${ }^{5}$ That the majority of referrals of minors came from the Cardiff series $(n=29)$ may be explained by the possibility that comparable referrals to other centres were filtered out at an early stage. Examining the Cardiff series in more detail, it is notable that 12 of the 29 referrals involved teenagers with a mean age of 15.5 years (A Tyler, personal communication). In three of these cases, the adolescent initiated the request and subsequently declined testing.

\section{Current guidelines concerning genetic} testing of minors

The policy recommendations for childhood genetic testing put forward by the Working Party of the UK Clinical Genetics Society (CGS) uphold acting in the best interests of the child or minor and preserving individual autonomy and confidentiality as central tenets:

"Given the dearth of evidence, it is the ethical consequences of childhood testing (loss of adult autonomy and confidentiality, and the possibility of causing harm to the developing child), together with the limited empirical evidence that is available, that has led us to advocate this cautious policy, erring towards a presumption of non-maleficence ("primum non nocere - the first goal is to cause no harm")". 8

Geneticists and ethicists in both the US and UK recommend testing only if there is clear benefit to the minor. The interpretation of "benefit" seems predominantly to be construed in medical terms and thus precludes childhood 
testing for untreatable, adult onset disorders. If an aim of genetic counselling is to help people make informed choices about their lives and, in particular, their reproductive plans, ${ }^{9}$ then it is argued that "to test children at an age when they are not considering or are not able to consider their own future reproductive plans would seem unnecessary and unethical". ${ }^{10} \mathrm{We}$ know, however, that at risk persons request $\mathrm{HD}$ predictive testing for many reasons other than to inform reproductive decision making ${ }^{112}$ and in many cases test applicants have completed their families already. ${ }^{13}$ Therefore, denying adolescents testing on the basis that they do not intend making reproductive decisions in the near future would be inconsistent with the approach taken to adult test applicants.

The International Huntington's Association and World Federation of Neurologists' policy statement ${ }^{4}$ recommends that testing be available only "to persons who have reached the age of majority." Bloch and Hayden ${ }^{7}$ assert that "children clearly cannot make an informed decision about whether to participate in predictive testing". The exclusion of minors from HD predictive testing is rationalised on the grounds of the lack of clear benefits of testing at this age, the possibility of third party pressures in the request, and the minor's inability to make an informed choice in this regard. ${ }^{1014}$ However, these reports are primarily considering third party requests for the testing of young children, rather than adolescents themselves actively requesting testing. Similarly, a survey of approximately 3000 health professionals in Britain, including clinical geneticists, genetic coworkers, paediatricians, haematologists, and other clinicians, showed that there was general agreement that childhood predictive testing for HD is best avoided. ${ }^{8}$ The same survey, however, indicated that $53 \%$ of the 260 participating paediatricians would test a 5 year old presymptomatically for $\mathrm{HD}$, at parental request, indicating a difference of opinion among health professionals.

It is conceded that there may be exceptional circumstances in which testing of minors is appropriate. ${ }^{8}$ While supporting a policy generally against childhood testing, Clarke and Flinter $^{15}$ provide for "particular, unusual circumstances in individual families" where testing may be appropriate and therefore advocate that each family situation be assessed individually. The predictive testing protocol of the UK Huntington's Prediction Consortium states that "the exclusion criteria set out in the protocol are not intended to be invariable, and every case should be judged on its merits". ${ }^{3}$ Ball and $\mathrm{Harper}^{16}$ advise that requests for HD predictive testing of children should be considered "only when actively sought by a subject who is sufficiently mature to make such a profound decision and is able to freely provide fully informed consent". Similarly, Wertz et al $^{17}$ conclude that "some minors may benefit from testing carried out to make plans for the future, provided that they themselves initiate the request".

\section{Research evidence concerning the impact of childhood testing}

The professional consensus against predictive genetic testing in childhood put forward by the CGS's report ${ }^{8}$ has been challenged in wider circles. Michie ${ }^{18}$ criticises the manner in which this standpoint has been reached, namely, on the basis of assumptions, rather than empirical evidence, regarding the effects of testing and through consultation within professional circles alone. The CGS's report concedes that the precedent set by HD predictive testing guidelines is based on "a consensus reached on the basis of the supposed likely effects (emphasis added) of such testing and not from the experience of harmful effects". The report continues to claim that "it is clear that predictive testing in childhood for late onset disorders ... can raise as many problems and as much anxiety as is generated by continuing anxiety about the child's genetic status". Contrary to what this statement suggests, there is no evidence concerning the relative costs of conferring a predictive test result in childhood versus continued uncertainty.

What the available evidence does show is that population based screening, as opposed to the screening of high risk groups, has been associated with more problems and these seem to be mitigated by the provision of good counselling. ${ }^{19}$ Michie and Marteau ${ }^{20}$ maintain that the Genetic Interest Group's ${ }^{21}$ arguments in favour of childhood carrier testing ("Early knowledge of carrier status could help the child adapt to the consequences of being a carrier over a period of time ... Facts of life are best absorbed slowly and when the moment is right rather than during a crisis over pregnancy") could be applied equally to adult onset conditions. We recognise, however, that there are varying degrees of disclosure and that these findings do not, in themselves, support predictive genetic testing at an early age. Outside the field of genetic screening and testing, empirical evidence suggests that being informed of a serious illness at an early age may facilitate adjustment and coping. Wertz et all ${ }^{17}$ report that "those who find out only in adulthood that a serious disorder such as HD exists in the family fare more poorly than those who know earlier". Adoption studies also support the psychological benefits of early disclosure. ${ }^{17}$

The potential adverse effects of minors undergoing tests for their genetic status are well documented. ${ }^{817}$ Less attention has been paid to the psychological harm that may be caused by withholding genetic testing. ${ }^{22}$ In this regard, Bloch et al ${ }^{3}$ comment that "the decision to postpone testing can never be taken lightly. The stress of undergoing testing, receiving a result, and adjusting to the new risk status must be weighed against the stress and uncertainty of living at risk for HD, the blow to the candidate's self-respect by being denied testing and the possible sense of humiliation and helplessness by having one's autonomy undermined". Indeed, psychological assessment of a cohort undergoing linkage testing showed that those receiving a test result fared better than those for whom the test was uninformative. ${ }^{24}$ 
Michie ${ }^{18}$ argues that practice should be based on empirical evidence, that it should not vary according to the subjective judgements of individual clinicians, and that policy decisions should also take account of the views of parents, children, and the public. Clearly, there is a need for research to inform practice in this area by, for example, exploring the psychosocial impact of childhood genetic testing in disorders where the ethical difficulties inherent in testing for an untreatable, late onset disorder do not arise. Other suggested areas of research include widening the debate concerning childhood genetic testing to include the attitudes of parents and children; exploration of psychological effects (including the development of personality, coping styles, and defense mechanisms) on people, confronted in their childhood or adolescence with their personal risk for adult onset diseases; and controlled studies of the short and long term effects of testing, and the mediators of these effects. ${ }^{1925}$ (Coping styles are conscious, rational ways of dealing with the source of anxieties, as opposed to defense mechanisms, which are unconscious strategies, designed to deal with the anxiety itself, rather than its source.) In addition, the consequences of withholding testing need to be documented. ${ }^{26}$

Despite the dearth of evidence concerning the impact of childhood genetic testing, there is a considerable body of publications that addresses the issue of adolescents' capacity to make competent decisions about their health and personal lives. Evidence from the law concerning consent to medical treatment, developmental psychology, and research concerning adolescent decision making presents a counterargument to the exclusion of under 18 year olds on the basis of their inability to make informed decisions about predictive testing.

\section{Legal evidence as regards competence to consent}

There is a general trend in the UK law to recognise the autonomy of the child and reduce the scope of parental authority. In recent years, children have been awarded a growing set of rights, including the right, if competent, to make major personal decisions. While existing case law surrounding medical care of children does not necessarily determine whether children can consent to genetic testing, it is the most directly applicable to this situation.

Recent developments in child law (Gillick $v$ W Norfolk \& Wisbech HA $1985^{27}$ and The Children Act 1989) have altered the legal status of children considerably. The statutory age of consent to medical treatment in the UK is 16 (Family Law Reform Act 1969, section 8; Age of Legal Capacity (Scotland) Act, s1). The Family Law Reform Act 1969 provides that the consent of a person aged 16 or 17 to medical treatment "shall be as effective as if he were of full age". If persons of this age or older lack the requisite understanding, however, they will be unable to consent, and younger persons who have sufficient understanding of the issue to make a choice will be able to give a valid consent even if they have not reached the statutory age. Therefore, the law supports an assessment, rather than an age based exclusion, approach as regards informed consent by minors.

The central issue is degree of intellectual and emotional maturity (sufficient understanding) rather than age. The problem arises in defining precisely what is required by way of understanding. It has been suggested that legal capacity must be determined in accordance with the particular decision in question so that the more serious the choice, the greater the understanding that is required. ${ }^{17}$ In this regard, the courts have recognised that, where possible, irreversible decisions should be left for children to make when they reach maturity. ${ }^{9}$ Considering the rapidly changing case law surrounding consent to medical treatment, Montgomery concludes that "it remains unclear how much a client must be able to understand to consent to the investigation of their genetic status".

\section{Defining decision making competence}

The abandonment of a strictly age based exclusion criterion requires the development of strategies for individual assessment. Such assessment needs to be based on some consensus regarding the key components of decision making competence. Definitions of this competence, however, vary considerably. For example, an ethicist's understanding of competence, which includes the capacity to have and apply a set of values, diverges from a purely legal standard. ${ }^{17}$ Within psychosocial research, conceptions of competence span a broad spectrum from a narrow information processing perspective, to skills based approaches, to a view of social decision making as a complex process that it is affected by many other factors besides intellectual capacity.

Early developmental theorists view competence as a composite of various internal attributes (cognitive abilities, personality characteristics, and emotional maturity) that, while basically biologically determined, are facilitated by social and environmental factors. According to this perspective, children's competence can be deduced from their performance of various intellectual tasks. However, "the once-tidy $\mathrm{Pi}$ agetian scheme of sequentially acquired cognitive structures has given way to a more complex picture, with multiple skills mastered to varying, but generally increasing degrees as people age". ${ }^{28}$ Piaget and his colleagues developed a stage theory of childhood cognitive development which describes a series of cognitive stages, characterised by specific modes of thought, through which a child moves.) Focusing on the cognitive aspects of decision making, Mann et a ${ }^{99}$ identify nine core skills that underpin decision making competence. They also recognise that social, emotional, and motivational factors play a significant role in such competence.

Challenging the "individualised" perspective of early developmental theorists is the view that 
competence needs to be defined, and only has meaning, with reference to the social, cultural, and institutional context. "Competence is more than a skill; it is a way of relating, and can be understood more clearly when each child's inner qualities are seen within a network of relationships and cultural influences". ${ }^{30}$ This approach argues that the development of competence is influenced by factors external to the person, such as parental attitudes and expectations, the state of medicine, the law, and the media, all of which are instrumental in forming a conception of children's abilities, rights, and responsibilities. Current conceptions of childhood and adolescence have an effect on both the development of competence and the way in which it is assessed. For example, children's competence would be enhanced where parents see them as responsible and trustworthy, informing them and involving them in decision making. Conversely, competence would be inhibited where parents adopt a controlling or protective stance toward their children, withholding information from them. Features of the clinical setting in which testing takes place could hinder adolescents' capacity to make competent decisions by, for example, a lack of space to sit and talk quietly. ${ }^{30}$

Judgements about decision making competence could be influenced by health professionals' attitudes towards the procedure, their perceptions of the risks and benefits involved, their levels of knowledge, and their tolerance for uncertainty. Research has shown that clinicians' practices regarding genetic testing are significantly correlated with their tolerance for ambiguity (ambiguity being interpreted as a type of uncertainty that cannot be represented by numerical probabilities). ${ }^{31}$ Health professionals, including medical geneticists, with low ambiguity tolerance were less likely to offer a new, low cost, accurate predictive test in the scenario of no others in their specialty offering the test. In addition, Geller et $a l^{11}$ note that low tolerance for ambiguity has been associated with paternalistic medical practices and not giving the patient autonomy in clinical decisions.

Much of the research concerning decision making in the context of risk is underpinned by normative theories of decision making, which prescribe ways of analysing and making decisions on rational information processing grounds. There is, however, widespread agreement that these models are inadequate in describing how people actually make decisions, hence the current interest in descriptive or naturalistic models of decision making. ${ }^{32}$ The shortcomings of systematic information processing models of decision making are particularly apparent in the context of genetic related decisions where people have to make choices based on probabilistic outcomes and in a context of much uncertainty. One of the few studies exploring how people actually made decisions related to genetic risk ${ }^{33}$ shows that decisional processes are not in accordance with normative decision making theories but are characterised by heuristic information processing. It may be that assessments of com- petence based on how people actually make decisions, rather than on an idealised model of decision making, will decrease the gap in competence between adolescent and adult decision makers.

\section{Do adolescents have the capacity to make a competent decision about predictive testing?}

From a cognitive perspective, competence in decision making involves the ability to process information logically so as to produce a correct choice, hypothetical and probabilistic reasoning about uncertain outcomes and alternatives, and having substantive knowledge in the area about which a decision is being made. The cognitive capacity to develop multiple hypotheses and to predict future possibilities (formal operational thinking in Piagetian developmental terms) generally develops around the age of $11^{17}$ and is well developed by the age of $14 .^{34}$ In terms of a cognitive, skills based understanding of competence, research evidence suggests that most people have achieved a reasonable level of competence in most of the core elements of decision making competence by the age of $15 .^{29}$ In a study examining competence to consent to medical treatment, Weithorn and Campbell ${ }^{35}$ found that 14 year olds show comparable levels of competence to adult study groups. Reviewing data on consent to medical research and treatment, Nicholson ${ }^{34}$ concludes that by the age of 14 years, adolescents have achieved "a level of competence in making decisions that differs from that of an adult only in terms of less experience and information and not in terms of ability to make a judgement"

The generalisability of these findings is limited in that, as mentioned above, the general stages of cognitive development differ according to educational, social, and cultural background (for example, in accordance with the amount of decision making latitude a person has in a family), resulting in wide variations in maturity. Furthermore, where decision making competence is acknowledged to be more complex than an information processing task, other skills will require assessment. Social, emotional, and motivational factors, apart from understanding or cognitive developmental level, may be equally or more important in the decision making context. Clearly, assessment based on an appreciation of the contextual rather than the individual nature of decision making competence is a more complicated matter.

Having reviewed research publications relating to the development of competence in decision making during adolescence, Mann et $a l^{9}$ assert that there are no psychological grounds for assuming that minors aged 15 years and above are unable to provide competent consent. In their review of research concerning children's ability to make informed decisions, Michie and Marteau ${ }^{19}$ conclude that "research has found children to be quite competent to learn decision making skills and to take control over decision making about their own health, 
especially when the scope of decision making is clearly defined". Korer and Fitzsimmons ${ }^{36}$ in their study of young people in HD families, concluded that "the young people concerned seemed able to discuss $\mathrm{HC}$ and its implications in a rational and thoughtful manner" and that "there is no evidence to support the supposition that young people are too emotionally volatile to cope with information about HC".

The capacity for adolescent competence in decision making is apparent but whether or not adolescents exploit this capacity is constrained or facilitated by a number of factors.

\section{Psychological and social constraints to competent decision making in adolescence}

Psychologically, adolescence can be viewed as a period of transition: a stage in the family life cycle where the person's task can be described as exploring and developing identity characteristics of the self different from the parents. It is a time of experimentation with new roles and fluctuation of values. ${ }^{17} \mathrm{~A}$ failure to weight the future adequately and to realise that values change over time has been noted as a problem of adolescent decision making. ${ }^{17}$ Peer pressure to conform (which is a threat to autonomous decision making) is strongest in early adolescence, before the age of $15 .^{29}$ Research findings concerning 14 to 15 year olds asked to make decisions in hypothetical medical dilemmas that included varying degrees of parental influence suggest that adolescents generally defer to perceived parental wishes. ${ }^{37}$ However, Sherer and Reppucci ${ }^{37}$ also note that the effect of parental influence varies according to the situation, with adolescents being "more likely to resist parental influence when the consequences or gravity of the decision has serious implications for the adolescent's health".

Adolescents may experience an external locus of control, perceiving other people, or events, as controlling them. ${ }^{17}$ This presents a threat to "decision control" (or willingness to choose), another hallmark of mature, competent decision making which is related to having an internal locus of control (holding the view that one is responsible for one's own actions and has control over one's destiny) and high self-esteem. ${ }^{29}$ Family structure and functioning have an important influence on adolescents' involvement and confidence in personal decision making, with decision making capacities being under used where adolescents do not perceive themselves as having choices in the first place. Furthermore, family dynamics characterised by conflict and low cohesion have been shown to limit adolescents' involvement in decision making. ${ }^{29}$

\section{An assessment approach towards} adolescent predictive testing requests

There seems to be a precedent in the case law surrounding consent to medical treatment for adopting an assessment, rather than an exclusion, approach in determining minors' competence to consent to predictive testing.
According to the General Medical Council Guidelines, it is the clinician's duty to make judgements about a child's level of understanding and maturity and to act accordingly. ${ }^{38}$ The geneticist then has discretion as to the particular time when information should be disclosed and studies from the Canadian Collaborative Study of HD Predictive Testing advocate that psychiatric and psychological assessment should be undertaken to determine the patient's readiness to proceed with predictive testing. ${ }^{39}$ Such assessment has not performed a gate keeping role, apart from the need to exclude the presence of serious psychiatric illness or suicidal risk in test applicants. Rather, psychiatric and psychological assessment has served to identify factors predictive of coping responses and has guided the planning of appropriate psychosocial support. Evaluation of the HD predictive testing protocol has been in terms of changes in the quality of life and psychosocial status of test applicants at follow up. As when HD predictive testing was first offered to adults, we advocate that assessment and testing of adolescents be carried out within the framework of a research protocol that documents their psychosocial status on requesting testing and at regular intervals following disclosure of the test result, as well as the assessment process itself.

Assessment of adolescents' cognitive competence and emotional maturity is arguably beyond the scope of a clinical geneticist. There are, however, professionals with expertise in this area who, for example, are called upon to assess children's decision making competence in child custody cases. We would therefore advocate the involvement of a child/adolescent clinical psychologist/psychiatrist during the assessment process.

Commenting on the testing protocol put forward by the UK Huntington's Prediction Consortium, Tyler and Morris ${ }^{40}$ note that "although no good information exists on the most appropriate age to offer testing, applicants still in their teens should be encouraged to take extra time to consider all the implications of being tested". Therefore we propose some general principles in developing an assessment approach to such requests.

The length of time that the adolescent has lived with the knowledge of HD in the family and his/her at risk status is of relevance. In evaluating the costs and benefits of continued uncertainty versus a predictive test result, a person will know the most about the risks that he/she has been dealing with the longest. ${ }^{28}$ The nature of adolescents' early exposure and adjustment to HD and being at risk is a significant determinant of their later adjustment to their genetic status. ${ }^{41}$ Hearing about how an adolescent coped with being informed about HD in the family and his/her personal at risk status may be an important predictor of his/ her coping skills to deal with a predictive test result. $^{42}$

Assessments of competence should be individualised and situation specific, ${ }^{43}$ global assessments of competence being poor yardsticks for particular situations. In addition, the focus 
of the assessment should be on the decision making process rather than on the final decision made, there being no "right" decision in this case.

Equivocal research findings as regards adolescents' decision making capacity reflect, in part, a lack of consensus as to how this competence should be defined and assessed. Despite the conceptual confusion in this area, we propose a number of factors that could form the basis of an assessment of the test applicant's competence to make a decision about predictive testing.

\section{EVALUATING COGNITIVE, EMOTIONAL, AND} SOCIAL MATURITY

Does the person show the necessary factual understanding of the nature and limitations of the test? Does the person show appreciation of the potential costs and benefits of the procedure and the test result, both personally and for his/ her family? Is there consistency and stability of the decision over time? Does the person show a fairly stable set of values that will continue into the future?

\section{ENSURING THAT THE PERSON IS ACTING} AUTONOMOUSLY

Is the adolescent the primary decision maker? Are there third party pressures evident in the request?

EXPLORING THE ROLE OF THE FAMILY CONTEXT IN THE DECISION (AND THE FUNCTION OF THE REQUEST IN THE FAMILY AT THE TIME)

Does the person understand the moral and family issues involved? What are the individual and family functions of the request? For example, is the request motivated out of a desire to confirm preselection beliefs? What is the family's way of discussing information and of sharing and making decisions?

ASSESSING THE PERSON'S EXPERIENCE AND CONFIDENCE IN MAKING MAJOR PERSONAL DECISIONS

How much decision making responsibility has the person had within his/her family? Has the family structure and functioning enhanced opportunities for developing decision making competence?

\section{Conclusions}

On the basis of our experience so far, we anticipate that clinicians will very rarely encounter the challenge of an adolescent actively requesting predictive testing of his/her own accord. In the UK, test applicants younger than 20 years constitute $1.9 \%$ of those persons tested between 1987 and $1994 .{ }^{44}$ It seems, therefore, that the need or wish to confirm one's genetic status is a concern that generally arises later in adult life.

It is arguable that self-selection (on the basis of good psychological functioning and positive appraisals of coping abilities) will operate in adolescent predictive testing requests as it has with adults. ${ }^{45-47}$ Furthermore, Kessler ${ }^{46}$ suggests that the $\mathrm{HD}$ predictive testing protocol may act as a screen to discourage all but the most motivated and determined people to proceed. We do, however, acknowledge that findings as regards the characteristics of the new cohort undergoing mutation testing suggest that they may not have the same levels of psychological adjustment and social support as seen with the linked marker cohort. ${ }^{48}$

Genetic testing is an area of medicine that presents both clinicians and patients with much uncertainty. New technologies create the possibility for a greater number of genetic diseases to be predicted, with varying degrees of certainty. "As technical knowledge expands, so does the power of the geneticist to influence the lives of clients who seek counselling about their own genetic status or the status of their children. In this developing context, the geneticist may experience most vividly the contrast between the beneficent care giver and the client whose autonomy must be respected". 6 The abandonment of "protectionist" policies in favour of adopting an assessment approach to adolescent predictive testing requests will require reliance on the clinical skill of appropriately trained professionals, rather than predetermined values and rigid exclusion criteria. We recognise that this would present a challenge to clinicians' tolerance for uncertainty. It is possible that the stringent pretest protocol serves not only to prepare and support test applicants, but also to reassure clinicians when faced with the many unpredictable aspects of patients' responses to genetic information. We would not, however, advocate enforcing rigid exclusion criteria and agree that "flexibility rather than immutable protocol in predictive testing programs better allows patients to receive the services they want and need". ${ }^{49}$

Julia Binedell and Jo Soldan are supported by a grant from the Medical Research Council and Jane Scourfield is supported by a Medical Research Council Special Training Fellowship in Health Services Research. We are grateful to Audrey Tyler for contributing to this discussion.

1 Huntington's Disease Collaborative Research Group. A novel gene containing a trinucleotide repeat that is expanded and unstable on Huntington's disease mosomes. Cell 1993;72:971-83.

2 Gusella JF, Wexler NS, Conneally PM, et al. A polymorphic DNA marker genetically linked to Huntington's disease. Nature 1983;306:234-8.

3 Craufurd D, Tyler A. Predictive testing for Huntington's disease: protocol of the UK Huntington's Prediction Consortium. F Med Genet 1992;29:915-18

4 International Huntington Association and the World Federation of Neurology Research Group on Huntington's Chorea. Guidelines for the molecular genetics predictive test in Huntington's disease. $\mathcal{F}$ Med Genet 1994;31:555-9.

5 European Community Huntington's Disease Collaborative Study Group. Ethical and social issues in presymptomatic esting for Huntington's disease: a European Community collaborative study. $\mathcal{F}$ Med Genet 1993;30:1028-35.

6 Pelias MZ. Duty to disclose in medical genetics: a legal perspective. Am $\mathcal{f}$ Med Genet 1991;39:347-54.

7 Bloch M, Hayden MR. Opinion. Predictive testing for Huntington's disease in childhood: challenges and imHuntington's disease in childhood: challeng
plications. Am f Hum Genet 1990;46:1-4.

8 Clinical Genetics Society. Report of a Working Party on the Genetic Testing of Children. Clinical Genetics Society, Genetic Testing of Children. Clinical Genetics Society,

9 Montgomery J. The rights and interests of children and those with mental handicap. In: Clarke A, ed. Genetic counselling: practice and principles. London: Routledge,
1994:208-22. 
10 Harper PS, Clarke A. Should we test children for "adult" genetic diseases? Lancet 1990;335:1205-6.

11 Simpson SA, Besson J, Alexander D, Allan K, Johnston AW. One hundred requests for predictive testing for Huntington's disease. Clin Genet 1992;41:326-30.

12 Evers-Kiebooms G, Swerts A, Cassiman JJ, van den Berghe $\mathrm{H}$. The motivation of at-risk individuals and their partners in deciding for or against predictive testing for Huntington's disease. Clin Genet 1989;35:29-40.

13 Holloway S, Mennie M, Crosbie A, et al. Predictive testing for Huntington disease: social characteristics and knowledge of applicants, attitudes to the test procedure and decisions made after testing. Clin Genet 1994;46:175-80.

14 Went L. Ethical issues policy statement on Huntington's disease molecular genetics predictive test. $7 \mathrm{Med}$ Genet 1990;27:34-8.

15 Clarke A, Flinter F. The genetic testing of children: a clinical perspective. In: Marteau T, Richards M, eds. The troubled helix: social and psychological implications of the new human genetics. Cambridge: Cambridge University Press, 1996 164-76.

16 Ball DM, Harper PS. Presymptomatic testing for late-onset disorders: lessons from Huntington's disease. FASEB 1992;6:2818-19.

17 Wertz DC, Fanos JH, Reilly PR. Genetic testing for children and adolescents: who decides? $¥ A M A$ 1994;272:875-81.

18 Michie $S$. The genetic testing of children: paternalism or empiricism? In: Marteau T, Richards M, eds. The troubled helix: social and psychological implications of the new human genetics. Cambridge: Cambridge University Press, 1996 177-83.

19 Michie S, Marteau TM. Predictive genetic testing in children: the need for psychological research. $\mathrm{Br} F$ Health Psychol 1996;1:3-14.

20 Michie S, Marteau TM. Response to GIG's response to the UK Clinical Genetics Society report "The genetic testing of children." 7 Med Genet 1995;32:838.

21 Genetic Interest Group Working Party. GIG response to the UK Clinical Genetics Society report "The genetic testing of children." f Med Genet 1995;32:490-1.

22 Sharpe NF. Presymptomatic testing for Huntington disease: is there a duty to test those under the age of eighteen years? Am 7 Med Genet 1993;46:250-3.

23 Bloch $M$, Adam S, Wiggins $S$, Huggins $M$, Hayden MR. Predictive testing for Huntington disease in Canada: the experience of those receiving an increased risk. $A m \mathcal{F} \mathrm{Med}$ Genet 1992;42:499-507.

24 Wiggins $S$, Whyte $\mathrm{P}$, Huggins $M$, et al. The psychologica consequences of predictive testing for Huntington's disease. $N$ Engl 7 Med 1992;327:1401-5.

25 Van der Steenstraten IM, Tibben A, Roos RAC, Van de Kamp JJP, Niermeijer MF. Predictive testing for Huntington disease: nonparticipants compared with participants in the Dutch program. Am F Hum Genet 1994, 55:618-25.

26 Marteau TM. The genetic testing of children. $f$ Med Gene 1994;31:743

27 Gillick $v$ W Norfolk \& Wisbech HA (1985). 3 ALL ER 402

28 Fischhoff B. Risk taking: a developmental perspective. In: Yates JF, ed. Risk-taking behavior. Chichester: John Wiley, 1992:133-62.
29 Mann L, Harmoni R, Power C. Adolescent decision-making: the development of competence. $\mathcal{F}$ Adolescence 1989 . ing: the devel

30 Alderson, P. In the genes or in the stars? Children's competence to consent. F Med Ethics 1992;18:119-24.

31 Geller G, Tambor ES, Chase GA, Holtzman NA. Measuring physicians' tolerance for ambiguity and its relationship to their reported practices regarding genetic testing. Med Care 1993;31:989-1001.

32 Shiloh S. Decision-making in the context of genetic risk. In: Marteau T, Richards M, eds. The troubled helix: social and psychological implications of the new genetics. Cambridge: Cambridge University Press, 1996:82-103.

33 Lippman-Hand A, Fraser FC. Genetic counseling: the postcounseling period. I. Parents' perceptions of uncertainty. Am $\mathcal{F}$ Med Genet 1979;4:51-71.

34 Nicholson RH. Medical research with children: ethics, law and practice. Oxford: Oxford University Press, 1986.

35 Weithorn LA, Campbell SB. The competency of children and adolescents to make informed treatment decisions. Child Dev 1983;9:285-92.

36 Korer JR, Fitzsimmons JS. Huntington's chorea and the young person at risk. Br $\mathcal{F}$ Social Wk 1987;17:521-34.

37 Sherer DG, Reppucci ND. Adolescents' capacities to provide voluntary informed consent. Law and Human Behavior 1988;12:123-41.

38 Green J, Stewart A. Ethical issues in child and adolescent psychiatry. F Med Ethics 1987;13:5-11.

39 Sharpe NF. Informed consent and Huntington disease: a model for communication. Am f Med Genet 1994;50: 239-46.

40 Tyler A, Morris M. National symposium on problems of presymptomatic testing for Huntington's disease, Cardiff. presymptomatic testing for

41 Wexler NS. Genetic "Russian Roulette": the experience of being "at risk" for Huntington's disease. In Kessler S, ed. Genetic counselling: psychological dimensions. New York: Academic Press, 1979:199-220.

42 Fox $S$, Bloch $M$, Fahy $M$, Hayden MR. Predictive testing for Huntington disease. 1. Description of a pilot project in British Columbia. Am $\mathcal{f}$ Med Genet 1989;32:211-16.

43 Devereux JA. Competence to consent to medical treatment in England and Australia. Dissertation, Oxford University, 1993.

44 Harper P, Houlihan G. Presymptomatic testing of Huntington's disease in the UK. Paper presented at the British Medical Genetics Conference, University of York, 11-13 September 1995

45 Codori AM, Hanson R, Brandt J. Self-selection in predictive testing for Huntington's disease. Am $\mathcal{F}$ Med Genet 1994, 54:167-73.

46 Kessler S. Predictive testing for Huntington disease: a psychologist's view. Am ₹ Med Genet 1994;54:161-6.

47 Tibben A. What is knowledge but grieving? On psychological effects of presymptomatic DNA-testing for Huntington's disease. Dissertation, Rotterdam University, 1993:233.

48 Adam S, Wiggins S, Lawson K, McKellin B, Hayden M Predictive testing for Huntington disease: differences in uptake and characteristics of linked marker and direct test cohorts. Am f Hum Genet 1995;57:1698.

49 Nance MA, Ludowese CJ. Diagnosis of Huntington disease: model for a predictive testing program based on understanding the stages of psychological response. $A m \mathcal{F} M e d$ Genet 1994;52:118-19. 